surgeon refused to operate because he thought the stones were blocking the ureter too low down to be reached. When the general died examination of the body showed the left kidney to be completely destroyed and occupied by several calculi. Schurrigius ${ }^{17}$ is certainly the first to employ the word " nepbro-lithotomy," the term employed by the older writers being "nephrotomy." Joachim Camerarius ${ }^{18}$ (A.D. 1598) relates a case in which a surgeon successfully extracted a stone that was plugging one of the ureters in a nobleman who was suffering agonies from renal colic and who demanded something to be done for his relief.

During the eighteenth century marked progress was made in our knowledge of renal disease. Human anatomy came to be more carefully studied, at least by those who aimed at being competent surgeons, and was expounded more fully to the student. The study of pathology was called into existence also. It is true that previously to this time Malpighi and Swammerdam, by the use of injections and with the aid of the microscope, had given a wonderful impulse to researches into the minute structure. Wharton had investigated the structure of the glandular organs, William Harvey (A.D. 1666-1723) had discovered the circulation of the blood, while Aselli had demonstrated the existence of lymphatic vessels; but Morgagni, who must be regarded as the founder of pathology, had still his work to do and to make his extraordinary influence felt. In Italy, a country which still retained its pre-eminence in medical science, we find during this century Pacchioni, Valsalva, Morgagni, Santorini, Mascagni, and Cotunni ; in France Winslow, D'Aubenton, Lieutaud, Vicq d'Azyr, and Bichât; while in Germany the accomplished Haller and Meckel were starting a school of medicine and preparing the way for the remarkable achievements of medical science in their country during the following 150 years. In Holland scientific progress was represented by Sandifort, Bonn, Albinus, Boerhaave, and Camper; while in Great Britain the two Hunters, Cowper, Cheselden, William Lawrence, Oruikshank, Charles Bell, and the Munros worthily developed anatomical and pathological science at home. The work of these men marked a great epoch in the development of the sciences and led up to an exact knowledge of surgery.

During this period there was considerable advancement made regarding the pathology of renal and vesical calculus and the situations in which they were liable to form. Previously the idea entertained was that stones were situated either in the substance of the kidney or in the hollow behind the kidney, and that the swelling or abscess associated with calculus ruptured into the kidney and caused a swelling externally. The most important contribntion to the subject is that given to us by the scholarly and accurate M. Hévin ${ }^{19}$ (1757) in his historical and critical researches into nephrotomy. He criticises the subject very severely and even the case of Consul Hobson he rejects. The following are his opinions in respect to nephrolithotomy :-

To establish the possibility of an operation it is not enough to presume that it will not prove fatal to the patient, but it is necessary that science can assure the execution of it. The plans for any great operation, which is wanting in the certain rules that science demands, can only be suggested by researches and views which may lead if possible to determine exactly the technique of the operation. Great operations are always very dangerous; therefore an operation whose execution is more uncertain than its success is not a lawful one, and can only be undertaken by a surgeon who is honest and religious.

With reference to cases in which suppuration has occurred and where fluctuation can be made out in the lumbar region, or if the abscess lies outside of the kidney, he recommends that the organ itself shonld be cut into and the stone removed from its peivis, by opening the kidney with the cantery, and when fluctuation is not distinct a trocar and canula should be inserted, and the wound stretched out until it is large enongh to permit the stone being removed. Mr. John Douglas, ${ }^{20}$ a surgeon of Edinburgh, records a case of old-standing renal calculus. The patient died in 1731 and at the post-mortem examination he says :-

Having always been of opinion that there was a stone in the right kidney, I resolved first to imitate the operation called by authors nephrotomy.

This he attempted, but the difficulty was so great on account of the very muscular condition of the subject that he failed to reach the stones and had to open the body in front.

$$
\text { (To be continued.) }
$$

\section{NOMENCLATURE AND CLASSIFICATION.}

\author{
By Charles Powell White, M.D. Cantab.
} F.R.C.S. FNG.

DEMONSTRATOR IN PATHOLOGY, THE YORKSHIRE COLLEGE, LEEDS.

A UNIFORM and logical system of nomenclature and classification is a great help in the study of any science. In medicine it is to be feared that such a system is impossible, but, at any rate, our present systems are capable of great improvement and it is my object to endeavour to show in what ways we can effect this improvement. Our conception of what a disease is will vary according to the standpoint from which we regard it. On the one hand, we can say that a disease is characterised by a definite causal agent, and on the other, that it is characterised by definite lesions. We, therefore, have two systems of nomenclature and classification-one based on cause and the other on effect. Both these systems are useful, and, indeed, necessary, but neither can take the place of the other. There are some names (e.g., syphilis) which have no inherent pathological meaning; these have mostly come to be regarded as having an etiological significance.

\section{NOMENClature.}

The chief factors concerned in producing the unsatisfactory state of medical nomenclature are $(a)$ the bias of antiquity, (b) the bias of authority, and (c) the progress of knowledge which has caused us to look npon diseases from a different aspect to that from which our forefathers regarded them. A name should comply with certain conditions: it should be classical, preferably Greek, in form; it should express by its derivation the condition to which it is applied; its form should correspond with that of other names expressing corresponding conditions; and it should not bo too cumbersome. Although we cannot hope to create an ideal system of nomenclature we can improve the present system to a great extent (1) by removing illogical and redundant terms ; (2) by always using corresponding terms to express. corresponding senses; (3) by making new names to express. new meanings instead of altering the meanings of established words ; and (4) in the case of alternative words by choosing. that which best expresses the condition.

1. By removing illogical and redundant terms. - The most. important of the illogical terms at present in use are the prefix " pseudo-" and the qualifying adjective "false." It would be a great improvement in medical nomenclature if these two terms were entirely removed. Why, for instance, should we call a fibroma of a nerve a "false neuroma"? We might with equal reason call a fibroma of the kidney a "false adenoma." These terms have arisen from the advance of pathological knowledge and the consequent alteration in the meaning of terms. For example, the term "tuberculosis" used to mean a disease characterised by the presence of certain structures called "tubercles"; now, however, it means a disease due to the bacillns tuberculosis and, in consequence, some diseases which, having the necessary tubercles as characteristics, would rightly be included in the term in its old sense, now are indicated by the term " pseudo-tuberculosis." Among redundant terms which might be discarded with advantage may be mentioned "atheroma," "epithelioma," \&c. The term "cirrhosis" should be used in a clinical sense only; "fibrosis" is a much better term to express the pathological condition of increase of fibrous tissue.

2. By always using corresponding terms in corresponding senses. -This is especially necessary in prefixes, suffixes, \&c. Terminations :- -trophy. - This termination, which really implies nourishment, is always used to imply growth, and it should be restricted to this sense. -plasia.-This implies development and it should have this meaning whatever prefix is attached to it. The usual definition of hyperplasia that is given is "bypertrophy by increase in the number of cells," as opposed to simple hypertrophy, which is " hypertrophy by enlargement of individual cells." This, however, implies a meaning of the termination which is not found in the other words of which it forms part; moreover, it is not sufficiently definite because it includes too much. For instance, the term "hyperplasia of the liver" does not indicate whether the change is due to an increase in the number of the lobules of the lixer or to an 
increase in the number of cells in each lobule. Again, hypertrophy of the kidney may take place in three possible ways. 1. By an increase in the number of tubules and glomeruli. 2. By an increase in the size of individual tubules, the number remaining the same : $(a)$ by an increase in the number of cells in the tubule, and $(b)$ by enlargement of individual cells. With the ordinary meaning of the terms 1 and $2 a$ would both be included in the term " hyperplasia," although they are totally distinct processes. I should call 1 "hyperplasia," $2 a$ "numerical hypertrophy," and $2 b$ "simple hypertrophy," and I should express the difference between hyperplasia and hypertrophy as exactly that between development and growth. That this is a true distinction is shown by the fact that hyperplasia, as I have defined it, only occurs during the period of development (at least, if compensatory in origin), and that simple and numerical hypertrophy are usually associated together. For instance, if one kidney fails to develop the other undergoes hyperplasia ; but if one kidney, having developed, undergoes atrophy or is removed the other undergoes hypertrophy. -ergia. - We have the termination "-trophy" and "plasia" to express growth and development, and I have proposed to introduce the termination "-ergia" to express functional activity ; thus "hyperergia" would mean "increased functional activity." -aemia.-This termination bas two significances, one referring to the condition of the blood and the other to the distribution of the blood in the vessels. This is unfortunate but it would seem to be unavoidable. The other terminations do not need discussion as there is no ambiguity in their use. Prefixes ; - Prefixes should always be used systematically and in different words should express the same meaning. The prefix $a$-or $a n$-, which really implies absence, is sometimes unfortunately used in the sense of diminution, as in the word a-trophy. In the word an-æmia it implies sometimes absence and sometimes diminution. Strictly speaking, "atrophy" should mean that the part though developed had not grown; it is, however, always used in the sense that the part which had grown afterwards has diminished in size. The prefix ana- is sometimes used in this sense, as in the term "anaplasia," which means " backward development." The prefix hypo-implies deficiency and should not be used as implying absence. The other prefixes need not be discussed. Suffixes :- -oma. The suffix "-oma" should be limited to the designation of the true tumours and it should not be applied to other conditions. The term " atheroma," besides being redundant, is used in more than one sense and there would seem to be little advantage in retaining it. -osis.- This suffix expresses (a) an overgrowth or multiplication of the structure designated by the root to which it is affixed. Thus fiorosis means an overgrowth of fibrous tissue and fibromatosis implies multiple fibromata. (b) Sometimes this suffix implies that the cause of the disease is expressed in the root to which it is attached; thus anthracosis is a disease due to coal-dust, aspergillosis is a disease due to the growth of an aspergillus, \&c. The suffix, therefore, has sometimes an anatomical, sometimes an etiological, significance. -itis.- This suffix has an anatomical significance and implies inflammation, and the root to which it is attached should express the organ or tissue which is inflimed. Some authors recently have expressed a wish that the term "inflammation" and the corresponding suffix should be removed from medical nomenclature. This, however, is impossible, as we should in that case have no terms to describe the inflammatory conditions as met with in the post-mortem room. A purely etiological nomenclature can never be suitable for the purpose of describing anatomical conditions, since a specific causal agent does not always give rise to the same morbid lesion, and no single lesion is always due to one and the same causal agent. ${ }^{1}$

3. By inventing new terms to express new meanings instead of altering the meanings of established words which already have a definite significance.-For instance, the word "diphtheritic" has long been used to describe a particular form of inflammation and there is no other word to express this meaning. When, however, the disease "diphtheria" was isolated and found to be due to a specific bacillus there was a natural tendency to limit the application of the term "diphtheritic" to conditions met with in diphtheria and so to alter its significance altogether. It is much more satisfactory to leave "diphtheritic" in its old sense and to use the term "diphtherial" as the adjective of "diphtheria."

1 The Relation between Cause and Effect in Disease, Brit. Med. Jour. Dec. 15th, 1900 .
This is done by many writers and editors at the present day and it would be a great advantage if it were the universal custom.

4. In choosing between two alternative names that one is to be chosen which best expresses the condition-Thus, "leucocythæmia" is to be preferred to "leukæmia," and "fibrosis" to " cirrhosis," \&c.

Nomenclature if tumours.-I bave given elsewhere ${ }^{2} \mathrm{my}$ views as to the nomenclature and classification of tumours, so that I need say very little about them here. Simple or tissue tumours are to be named by affixing the suffix "-oma" to the root expressing the name of the tissue which constitutes the essential part of the tumour. Exceptions occur in the case of epithelial and endothelial tumours since the terms "epithelioma" and "endothelioma" have been applied to malignant growths. The place of these terms is taken by the terms " papilloma," " adenoma," " angeioma." I should call any simple epithelial tumour in which the epithelium forms tubes and spaces lying in a connective tissue stroma an " adenoma," whether the growth starts from a gland or from a surface epithelium. Carcinomata are to be named according to the kind of epithelial cells of which they are constituted; such words as "adeno-carcinoma" are not necessary and only lead to confusion. Cancer.-Most writers at the present day use the term "cancer" as synonymous with "carcinoma." In this sense the term is redundant and therefore unnecessary. It would be much more satisfactory to revert to the older meaning of the word as signifying any malignant growth, since we often have occasion to speak of malignant growths without specifying whether we are speaking of carcinoma or sarcoma.

Another direction in which reform is desirable is in the use of the word " coagulate." This is applied indifferently to the change which occurs in albuminous bodies by the action of heat, alcohol, \&c., and to the changes occurring in the clotting of blood or muscle. There would seem to be no reason for this double use of the word.

\section{Classification}

It may be said at once that it is absolutely impossible to find a system of classification which shall be useful for all purposes. A disease is not a definite entity, but is an action. It has been defined as "an abnormal interaction between the structure of the living body and its environment." Our conception of disease is thexefore inseparable from life. For example, we can speak of lead intoxication as a disease, but it is not the lead that is the disease, nor is it the effect that lead produces on the body, but it is the action of the lead on the living body. Since, then, diseases are not entities we cannot classify them in the same way as we classify material substances; we can only classify them according to the cause of the disease or according to the effects that are produced on the body. Olassification by cause is useful for the systematic consideration of diseases, as, for example, in a text book of medicine or surgery. When, however, we have to do with clinical symptoms or morbid conditions of the different organs the most useful system of classification is by the effects produced on the body by the causal agent. Whenever we make a diagnosis we make a mental classification by effect. We first observe the effects of the disease and then by successive stages we arrive at a conclusion as to the cause. We thus in diagnosis and in the post-mortem room argue from effect to cause and not vice vers $\hat{a}$; in the systematic study of diseases, on the other hand, we often argue from cause to effect.

The confusion arising from the use of an illogical and unscientific system of classification is seen in the result of classifying tumours on an embryological basis. In this system carcinoma is said to be epi- or hypo-blastic in origin; those, therefore, who adopt this system must, if they are consistent, deny the existence of carcinoma arising from the renal, testicular, ovarian, or uterine epithelium. Moreover, since the neuroglia is almost certainly epiblastic in origin, the gliomata should be included among the epiblastic rather than among the mesoblastic tumours. At a recent meeting of the Pathological Society of London one of the members is reported to have doubted the existence of carcinoma arising from the hepatic cells because it has been suggested that these cells are of mesoblastic origin. 1 There is no reason whatever why we should classify tumours according to the layers of a three-layered embryo; it is much more scientific

2 Journal of Pathology and Bacteriologg, vol. vi., p. 220. 3 Harry Campbell : The Causation of Disease, London, 1889 
to classify them on a histological basis, since we can observe their structure and can only infer which embryonic layer they belong to.

Any classification should satisfy certain conditions. 1 . It should be based on observable facts and not on inferences. 2. In dividing a class into sub-classes the basis of division must be the same for each sub-class formed ; thus it is wrong to divide cirrhosis of the liver into multilobular, monolobular, and syphilitic, as is done in many text-books. 3 . The sub-classes of any class should be mutually exclusive-i.e., there should be no overlapping. 4. The sub-classes when added together should include the whole of the class and no more.

Classification by cause.--The factors concerned in the causation of disease can be divided into (a) extrinsic and $(b)$ intrinsic. A cause which is extrinsic as regards a particular organ may be intrinsic with regard to the whole body. Causal factors can also be divided into (a) essential and (b) adjuvant, the essential cause being that without which the disease could not occur and the adjuvant causes being those which assist in the production of the disease without in themselves being individually necessary. We can therefore classify diseases as follows. 1. Diseases in which the essential factor is extrinsic- $-(a)$ parasitic diseases ; (b) intoxications; (c) diseases due to physical or chemical irritants; (d) diseases due to alteration in amount or pressure of the surrounding medinm; and $(e)$ diseases due to altered nerve-supply, \&c. The processes concerned in these diseases are inflammation, consecutive atrophy, consecutive hypertrophy, degenerations, \&c. 2. Diseases in which the essential tactor is intrinsic. For example, those diseases which are characterised by the processes primary atrophy, progressive hypertrophy, tumour formation, maldevelopment, \&c. The actual nature of the intrinsic factors in the causation of disease is unknown to us ; we cannot, therefore, subdivide the second class in the same way as we can the first. It is obvious that it is very difficult to allot a place to every disease in this system of classification.

Classification for general pathology.-General pathology is the study of pathological processes, their causes and effects, without reference to any particular locality or disease. In any scheme of classification for general pathology we must provide for certain processes or conditions which may be called "physical"-namely, those processes or conditions which depend purely on physical causes. Such are the distension of blood-vessels in obstruction of the circulation and the emptying of the vessels beyond the obstruction, the distension of ducts from obstruction, wounds, deformities, \&c. We might classify the pathological processes as to cause in accordance with the scheme given above, dividing them into (a) consecative processes, and (b) primary processes. We should subdivide (a) according as the processes are the result of irritation, alteration of blood-supply, nerve stimuli, functional activity, \&s. This method has the disadvantage that the processes "atrophy," "hypertrophy," \&c., would appear under $(b)$ and also under most of the subdivisions of (a). We might, on the other hand, classify them according to the nature of a process thus: (a) alterations of development; $(b)$ alterations of growth; $(c)$ alterations of functional activity; (d) degenerations, \&c.; and $(e)$ physical. The best method, however, is as to the results of the processes.

If we consider the strictly pathological processes we find that we can divide them into three groups. 1. Those which are characterised by a destruction or diminution of tissue or functional activity (destructive processes). Such are atrophy, hypo-ergia, \&c. 2. Those which are characterised by a replacement of tissue or fanctional activity lost, or by an increase to meet extra demands (reparative processes) Such are repair, regeneration, and the compensatory processes. Ioflammation would also come under this heading as a preparation for repair. 3. Those which are characterised by an actual increase of tissue or functional activity beyond the needs of the organism (constructive processes). Such are tumour formation, \&c. I should sub. divide the first group into primary and consecutive processes, and the third into those which are collateral, such as hypertrophy from increased blood-supply without any demand for extra work, and those which are progressive, such as tumour formation, \&c.

Our knowledge of the infiltrations is too incomplete to allow us to assign them their proper place in this classification. In accordance with custom they may be provisionally classed with the degenerations.
SChame of Chassification for General Pathology.

A. Etiology, including parasitology.

B. Developmental errors : monsters ; malformations (aplasia hypoplasia, hyperplasia, and kakoplasia-i.e., irregular development) and malpositions.

C. Physical processes : deformities ; displacements ; solution of continuity; distension of tubes and spaces; and blocking of tubes and spaces.

D. Cessation of physiological processes : necrosis.

E. Destructive processes : consecutive (atrophy, anergia, \&c.; dogenerations, \&c.) ; and primarv (atrophy, anergia, \&c.).

F. Reparative processes : inflammation, repair, regeneration; compensatory hypertrophy ; compensatory hyperergia; and compensatory metaplasia.

G. Constructive processes : collateral--e.g., hypertrophy from increased blood-supply; and progressive (progressive hypertrophy, progressive hyperergia, progressive metaplasia, and tumour formation).

Classification for macroscopic morbid anatomy (museum or post-mortem room).-In the arrangement of a museum one section should be devoted to specimens illustrating general pathological processes. This section is best arranged on an etiological basis and it should contain specimens illustrating the various processes and also typical specimens illustrating diseases which are not limited to any particular organ, such as tuberculosis, metastatic carcinoma, \&c. It should also contain specimens of the various parasites, animal and vegetable. The rest of the museum should be divided into sections corresponding with the different systems, each of these sections being subdivided according to the organs in the system. In the case of the bones classification should proceed according to the scheme to be given before subdividing according to individual bones, and this should be the case with regard to the joints, muscles, \&s. The primary classification should be based on the macroscopic appearances and not on etiology. Cause should be used as a basis of subdivision. In this scheme the inflammatory conditions present the greatest difficulty. I think that the best division is into non-suppurative, suppurative, and ulcerative; they could then be subdivided into diffuse and nodular conditions. Fibrosis (sclerosis in bone, \&c.) should be accorded a separate class because it is not necessarily a post-inflammatory condition. Inflammatory conditions and tumours should, if possible, be subdivided according to the portion of the organ affected; thus, tumours of bone should be divided into central and peripheral growths. Cathcart $^{\bar{D}}$ advocates the classification of a museum on an etiological basis, but his system is open to many objections. In the post-mortem room, as at the bedside, we argue from. effect to cause and not vice versâ. If, then, the museum is to be of assistance in clinical work the primary basis of classification should be the effects produced on the organs. by disease, cause being used as a basis of sub-classification. Another objection to Oathcart's system is that similar conditions of an organ, instead of being placed together, would be found under several headings; there is also an unjustifiable separation of syphilis from tuberculosis, the one being called a blood poison and the other a local irritation.

Scheme of Classification of the Morbid Conditions of the DIFFERENT ORGANS.

A. Alteration in form or position : malformations; deformities; malpositions ; and displacements.

B. Alteration in structure : metaplasia-e.g., ossification of tendons.

C. S Jution of continuity : wounds, fractures, \&c.

D. Repair-e.g., cicatrices, healing of fractures, \&c

E. Disturbantes of circulation : hyperæmia, embolism, \&c.

F. Retrogressive changes : atrophy; and fatty, calcareous changes, \&c.

G. Inflammatory conditions: non-suppurative (diffuse and nodulare.g.. tuberculosis, \&c.); suppurative (diffuse-e.g., cellulitis, and abscess : and ulcerative).

H. Fibrosis (sclerosis)

I. Necrosis (gangrene).

J. Hypertrophy: compensatory and progressive.

K. Tumours.

L. Cysts

M. Animal parasites in situ.

Classification for clinical purposes. - It is not possible to give a complete scheme of classification for clinical purposes, since it will necessarily vary according to the organ which is affected. The natural system is one based on the symptoms to which the diseases give rise. Thus, we speak of diseases of the liver associated with ascites or jaundice and we divide affections of the serous membranes into those with and those without effusion, \&c.

Classification for histological purposes.--In classiñcation for histological purposes we use as our basis the histological characters of the lesions found in the disease; thus, we divide inflammations of the kidney into glomerular, tabal, and interstitial nephritis. In describing the microscopic

5 Classification in Pathology, Edinburgh Medical Journal, 1896 vol, xlii., pp. 37,141 . 
appearances of any lesion we should not use words implying, an etiological classification such as "syphilitic cirrhosis," "scarlatinal nephritis," \&s. As examples of these varions systems of classification let us consider cirrhosis of the liver. 1. Olassification according to the cause: (a) alcoholic; (b) syphilitic ; $(c)$ biliary ; and $(d)$ post-febrile, \&c. 2. Classification according to the symptoms : (a) cirrhosis with ascites; and $(b)$ cirrhosis with jaundice. 3 . Classification according to the macroscopic appearances: (a) small cirrhotic liver ; and (b) large cirrhotic liver; or (a) hobnail liver, and $(b)$ smooth cirrhotic liver. 4. Classification according to the histological appearances : (a) multilobular; (b) monolobular; and (c) pericellular. 5. Olassification according to the nature of the fibrotic process : (a) inflammatory ; (b) replacement ; and (c) progressive. It will be noticed that no two of these classifications coincide and that a system which is suitable for one purpose is not suitable for another.

In the foregoing remarks I have endeavoured to indicate some of the rules that should guide us in the construction of names and schemes of clsssification. It has been impossible to give more than a few examples, but those given are, I think, sufficient to show that nomenclature and classification should proceed according to definite rules and not in the hap-hazard manner which is too common at the present day. Leeds.

\section{THE ROYAL COMMISSION ON SOUTH AFRICAN HOSPITALS.}

(Continued from p. 65\%.)

\section{III.}

IN our issue of March 2nd we gave an abstract of the report of the Commission as far as it dealt with matters up to the occupying, and advance from, Bloemfontein. We now continue the abstract of the report as it deals with the advance to Pretoria and the incidents which occurred on the way.

The advance to Kroonstad was, say the Oommissioners, similar in most ways to the advance to Bloemfontein, though the condition of affairs was somewhat better. The sick and wounded accumulating during the advance were sent back to Bloemfontein, except some who were detained for a time at Glen and at Karee. As to the passage by railway from the rail-head to Bloemfontein the Commissioners say:-

As a rule the men were properly supplied with necessaries. but there were cases of prolonged detention when thure was a deficiency of supplies. And the open trucks which bad generally to be used for the less serious cases must have caused hardship to their occupants. We ought, however, in considering this subject, to observe once for all, with regard alike to this particular advance, to the advance upon Bloemfontein, and also to the subsequent advance of the army to Johannesburg aud Pretoria, that, though men may have fallen out
from the ranks during the march, there is no real foundation for the suggestion that to any appreciable extent sick or wounded men were leit lving on the veldt unattended.

There is one incident connected with this advance referred to in $\mathrm{Mr}$. Burdett-Coutts's evidence whinh we should particularly notice. It concerns the repulse of the Inniskillings and the Scots Greys. It is said that the wounded were left unattended from 9 A M. to 4.30 P.M. and that they were then taken to a tin hut by Major Eames, of the New South Wales Bearer Company, and left in charge of a civil surgeon there; that two be evacuated; that he protested, on the ground of the condition of the patients, against the order, but that he was obliged to carry it out notwithstanding his protest, and that the sick and wounded were sent away by ox-wagons, excepting only three officers who were detained in the tin hut under the care of a doctor. Mr. Burdett-Coutts adds that it appeared to him that the detention of these three officers alone was an unfair distinetion. The facts of the case appear to be as hereafter stated, from which it will appear that any suggestion of unfairness in
the treatment of the efficers and privates is whally unfounder. The the treatment of the efficers and privates is wholly unfounder. The
troops were mounted and had been fighting a skirmishing action in troops were mounted and had been fighting a skirmishing action in When the loss to the Innirkillings and Scots Greys occurred the wounded could not be collected until some first to come up were the ambulances of the New South Wales Ambulance Corps which was well in front and provided with good horses instead of mules. These ambulances at once gathered with good horses without any undue delay and took them first to a Kaffir kraal where they were tended for a night, three surgeons being present they of them a gentleman temporarily serving as a private. The next day the men were removed to a tin house at Ventersberg Siding and there they were operated on and carefullv and properly attended to by the three surgeons, assisted by Mr. Cheatle, one of
the civilian consulting surgeons. Then the surgeon who hat been the civilian consulting surgeons. Then the surgeon who hat been
previously serving as a private volunteer was left in charge after his previously serving as a private volunteer was left in charge after his
skill had been tested by the other surgeons. Some days after this the wounded in the hut had to be removed, so far as they could be withou injury to themselves, on account of the military situation and the fact hat the enemy were threatening the position. Before the removal in their opinion, kind was made in respect of the removal by any surgeon. Th any kind was made in respect of the removal by any surgeon. They all agreed that the patients who were sent could properly be removed.
Three patients, and three patients only, were kept because their cundition was such that they could not be transported with safety to themtion was such that they could not be transported with safety to them-
selves. Of those, two were officers and one was a private. Their selves. Of those, two were officers and one was a private. Their
injuries were very severe. They were kept wholly irrespective of rank injuries were very severe. They were kept wholly irrespective of rank
and entirely upon considerations of their medical condition. That no and entirely upon considerations of their medical condition. That no question of rank entered into the determination of the matter is obvious, not only from the pature of the wounds of the men who re-
mained. but from the fact that amongst the patients who were sent mained, but from the fact that

\section{Glen and Karee Siding Hospitals.}

We may here deal shortly with the condition of the hospital at Glen. Between 200 and 300 patients were kept there during the advance unde Complaints have been made, and justly, with regard to the site of the homplaints have been made, and justly, with regard to the site of the Lying in a hollow, it was liable to become extremely damp during wet weather, and, accordingly, we find that the men in the tents did complain greatly of the state of the ground on which they were lying, and said that they had become worse instead of better since they had been placed there. The Rev. Robert Mcclelland, acting as a Presbyterian chaplain to the forces, who gave evidence as to the condition of the hospital, visited it on the 28 th April, and he points out how, on
removing the waterproofs under the blankets of the men, he discovered a fungus growth existing there. This is sufficient in itself to show the nature of the ground. We inquired from the officer who selected the site (Major Faunce) how it came to be chosen. He said that it was the only possible site that could be selected, because there were military reasons against encamping on higher ground, and then goes on to say: "We should have been behind the outposts and there were other military reasons; in fact. there was no other ground at Glen where we could have encamped, aud it was the only clean piece of ground." It is difficult for us to judge whether another and better site might not have been selected. The hospital was, in fact, evacuated shortly after Mr. McClelland visited it. Apart from the nature of the site there are not many complaints with regard to this hospital except hospital being used as a tixed one. Probably it is to this evacuation hospital being used as a tixed one. Probably it is to this evacuation that Mr. Burdett-Coutts alludes when he speaks of a convoy being subjected to nameless torture owing to the patients being huddled together in rough springless ox-wagons and jolted over spruit and drift
for 40 miles. In his evidence he informed the Commission that in his statement be referred to a convoy which came from Glen some time about the 28th April, and as the 14th Brigade Field Hospital reached Kroonstad on the 14th May Mr. Burdett-Coutts's date would coincide
closely with the period of its evacuation. It should be noted, however, closely with the period of its evacuation. It should be noted,
that Glen is only 14 miles from Bloemfontein and not 40 miles.

With regard to the temporary hospital formed at Karee it appears to have been overcrowded and to have had the usual drawbacks attributable to a hospital formed under its conditions.

\section{KROONSTAD.}

With regard to Kroonstad itself the town was small and the buildings which had to be taken for hospitals - the only existing hospital being full of Boers and British prisonerswere not well suited for the purpose. There were undoubtedly great pressure and corresponding discomfort for the patients, but after the line to Bloemfontein was open the state of matters improved. The army of occupation arrived on May 12th and soon after the sta'e of matters is well shown in the following extract from the report:-

On the 16th May Major Ford of the 18th Brigade Field Hospital took harge of the buildings. Several witnesses bear testimony to the great credit due to this officer for what he did under very trying and adverse conditions, and in our opinion the work he did was, under the circum stances, remarkably good. Those difficulties, as may be easily seen, were very great. For the first few days the staff of the 19th Brigade Field Huspital had practically alone to look after all the sick and wounded in the lown though the field hospital of the 3rd Cavalry Brigade appears to have been the

Such a-Captain McMeekan.) look after the patients requiring attention. At the time that Major Ford took over the buildings there were in the Kroonstad Hotel 16 officers and 127 men (not 200 as one witness has stated). These men were placed chiefly in the dining-room of the hotel, and all, with the exception of about a dozen, had mattresses. With regard to these latter men, directly Major Furd took command of the building he at patients in the hotel were provided for. Dr. Manning. a local patients in the hotel were provided for. Dr. Manning. a local
doctor, was placed in charge of the Grand Hotel to which about 150 patients were removed from the field hospitals on Lord Roberts's patients were removed from the field hospitals on Lord Roberts's
advance. Dr. Manning as a civil surgeon was, of necessity, not much experienced in military hospitals, but did well under the circumstances, having to assist him only 15 untrained orderlies. This hotel had not been prepared for the reception of the patients when they first came in, and the rooms in which they were placed were very inconvenient. Great discomfort was, of necessity, suffered by the men, and there was great difficulty in attending to them at all. The men bad to lie on the

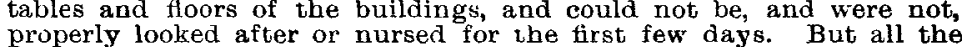
properly looked after or nursed for the first few days. But all the patients within three days after the occupation of the hotel had change of clothing provided for toem within two days after the hotel was first taken. On the 22nd May Major Ford cleared sume of the patients from this hotel to the Rest Camp which had been prepared, and within the next three days the hotel was cleared of all the patients except a few officers who were left in the small rooms on the upper floor, where, baving their own servants, they could be properly attended to. There
lhese officers remained until the hotel was closed altogether as a 